\title{
A Human Factors Perspective on Helicopter Human External Loads
}

\author{
Randa L. Shehab and Robert E. Schlegel \\ School of Industrial Engineering \\ University of Oklahoma \\ Norman, OK 73019
}

\begin{abstract}
Human external loads (HEL) refer to operations where humans are transported while suspended below a helicopter. HEL operations are often required to access remote work sites, to access power lines in need of maintenance and repair, for transport of offshore ship captains, and for rescue operations. This paper reports a human factors investigation of HEL operations and the devices used to secure HELs involved in work (non-rescue) activities. The goal of this investigation was to determine if HEL operations pose a significant safety hazard. Specifically, the paper describes the various devices used to secure HELs, the accident history associated with HELs, and human factors recommendations for the regulation of HEL devices and operations. Review of 616 helicopter accident reports revealed that only $1.5 \%$ of the accidents occurred during HEL operations and only $0.5 \%$ were directly attributable to the presence of an HEL.
\end{abstract}

\section{INTRODUCTION}

The term human external load (HEL) refers to the suspension of a human from a helicopter. HELs exist for a variety of reasons. Workers may be transported to remote, inaccessible work sites, injured victims or victims trapped in hostile environments may be rescued, or rescue workers may be transported to the rescue site. Existing FAA regulations address the physical and structural characteristics of external load (EL) operations in general. However, little consideration has been given to the issue of humans as external loads. The introduction of a human as a suspended load warrants investigation of safety and comfort issues extending beyond the physical characteristics of the load transport.

\section{THESIS}

The Rotorcraft Standards Directorate of the Aircraft Certification Service has questioned if a large number of accidents involve the transport of human external loads using rotorcraft. More specifically, the devices used to secure the human have been considered deficient with regard to safety. This study was contracted by the FAA to investigate the use of humans as external loads in occupational (non-rescue) applications. As the FAA's jurisdiction lies in commercial and civil aviation, no attempt was made to evaluate military and rescue operations. Although HEL operations have been in existence for many years, there has been little investigation of the viability of humans as external loads. Information regarding the design of HEL devices along with the accident history for HELs was examined to address these questions regarding HEL safety.

\section{SOURCES OF INFORMATION}

A survey of devices currently used to secure HELs was conducted by contacting companies and organizations involved in HEL operations. The response from most endusers was less than enthusiastic, and those organizations that had experienced accidents or incidents were reluctant to discuss HEL issues. More success was encountered through contacting manufacturers of HEL devices, many of whom supplied product catalogs and videos.

In order to document the magnitude of problems associated with occupational HEL operations and to understand how the problems are manifested, several accident databases were queried for HEL-related incidents. Database retrievals were obtained from the NASA Aviation Safety Reporting System (ASRS), from the FAA Accident/Incident Data System (AIDS), and from records of the National Transportation Safety Board (NTSB). Device information was also obtained from local government agencies. Rescue organizations provided suggestions and anecdotal stories of HEL operations.

\section{HEL Devices}

\section{FINDINGS}

There are numerous devices used to secure HELs for helicopter transport operations. Although there is overlap in the functionality of the different devices, they can be categorized according to their primary use for either long-term or short-term applications. Long-term applications include activities such as long-distance transport and working from a suspended platform or basket. The important characteristic of long-term HEL devices is that the user is minimally constrained by the HEL device and is afforded some degree of 
mobility. It is critical that the HEL device does not subject the worker to additional strain on the body and that the device does not restrict body movements essential for performing the work task.

Short-term applications of HEL include rappelling, short hauling, and rescue operations. Devices used in such applications are directly attached to the user for the duration of the activity, which usually involves transport to a near location. This category can be further subdivided into active users and passive users according to the level of user involvement in the HEL operation. Active user devices require the passenger to actively participate in the lifting operation by maintaining a grasp on a center bar or hoist rope for balance. Passive user devices transport injured or impaired people who are unable to assist in their rescue. Typically, rescue personnel are required to assist passive users in order to position the user in the HEL device. Figure 1 depicts the categorization of HEL devices and provides examples of each category.

\section{Accident/Injury Data}

There was minimal overlap in the specific accidents reported in the databases. All information contained within the NASA ASRS data system is voluntarily submitted. Thus, it is subject to self-reporting biases and is not corroborated by the FAA or the NTSB. The attractive feature of this reporting system is that most events are described in a narrative provided by the event reporter. The report provides information regarding the reporter's role in the event, the accident location, flight conditions, anomaly information, the narrative, and a synopsis of the accident. No identifying information is provided. Consequently, the ASRS data could not be cross-referenced with the other databases.

Seven events involving helicopter external loads were identified from the ASRS database spanning from 1985 through 1996. None of the events involved accidents with human external loads. However, one reporter described an HEL operation involving a fully harnessed photographer standing on the helicopter skid to photograph the pilots. The reporter felt that this situation was unsafe and requested that FAR 91.107 be modified to address such photography (HEL) operations.

One of the most comprehensive databases reviewed was the Federal Aviation Administration's Accident/Incident Data System (AIDS) available from 1973 through 1997. This database details accidents for aircraft under the FAA's jurisdiction. Each rotorcraft accident report was reviewed to determine if external loads were the primary hazard in the event, and particularly, if human external loads were involved. Of the 473 rotorcraft accidents listed in the AIDS, $282(60 \%)$ occurred during external load operations, but only $86(18 \%)$ resulted directly from external load complications. Of this subset, $98 \%$ (84 out of 86 events) involved sling line/load operations. The remaining $2 \%$ (2 out of 86 ) involved human external loads, with the HEL as the primary hazard.

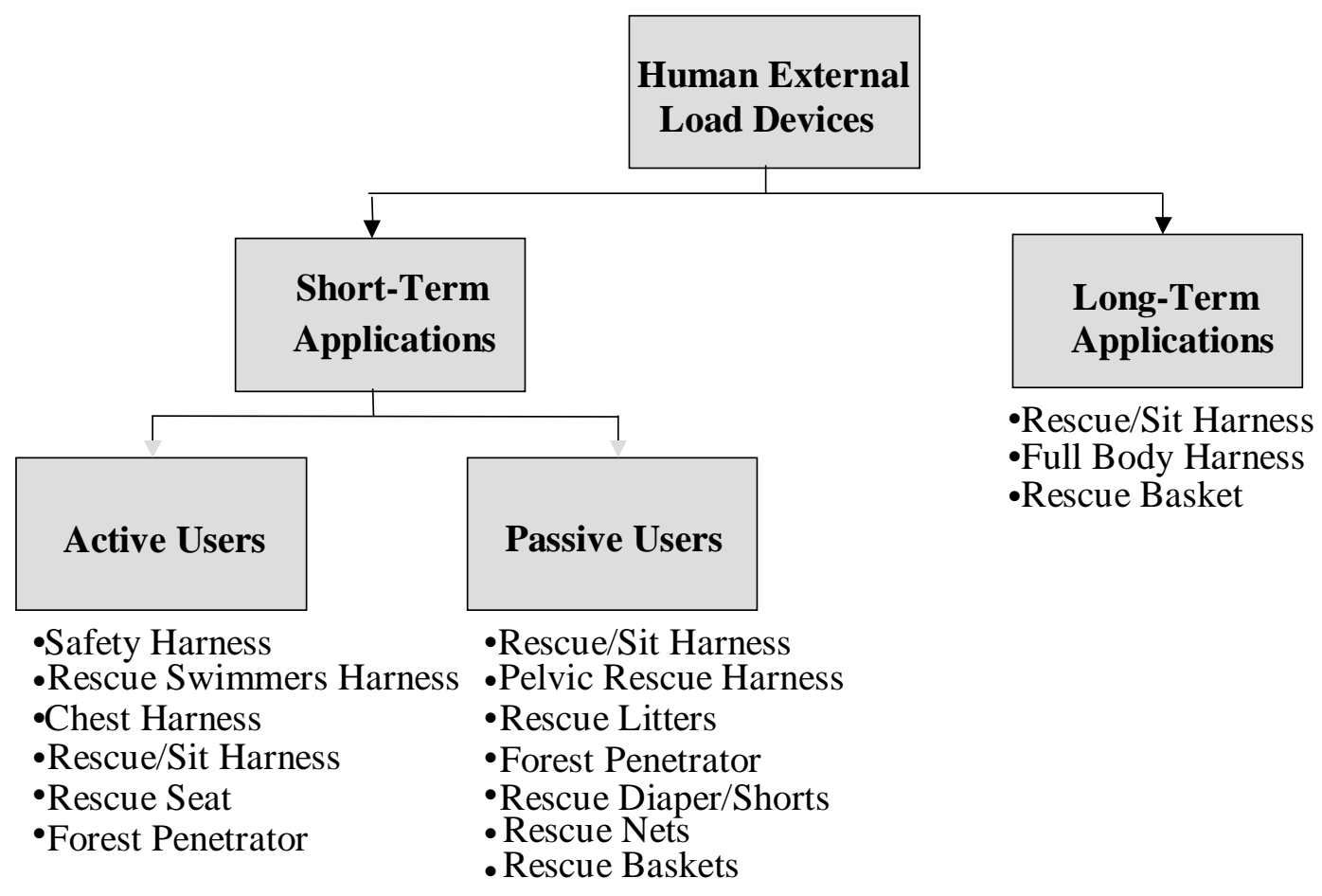

Figure 1. Categorization and Examples of HEL Devices. 
The National Transportation Safety Board (NTSB) maintains a detailed database of all major transportation accidents. The NTSB database includes an accident narrative and a description of the events leading to the accident. Review of 244 rotorcraft accidents that occurred between 1988 and 1996 revealed that $47 \%$ (115 of 244) occurred during external load operations while $9 \%$ (23 of 244) were a direct result of external load operations. The use of a sling line to transport the external load was a significant factor in $18 \%(21$ of 115) of the external load accidents. Although four accidents involved human external loads, only $2 \%$ ( 2 of 115) were directly attributable to the HEL operation.

The FAA AIDS and NTSB databases were merged to provide a comprehensive collection of 616 accident/incidents. Each accident was classified into one of twenty categories of accident causation. A single causal factor was identified for each accident. Figure 2 presents the categorization as a percentage of total accidents/incidents.

The use of human external loads was identified as the most significant contributing factor in only three accidents $(0.5 \%)$ although nine total events $(1.5 \%)$ involved HEL operations. A summary of these HEL accidents/incidents is presented in Table 1. Each of the three HEL-related accidents resulted in the fatality of the user and two occurred during authorized work assignments. Although HEL was involved in six other recorded events, it was not a causal factor and each accident was attributed to a non-HEL primary cause.

\section{DISCUSSION}

This review failed to demonstrate a serious safety issue with HEL operations; across 25 years of data (1973 - 1997), only nine accidents involved HELs. More significantly, only two of those nine accidents were directly caused by authorized HEL operations. HEL operations are a relatively minor safety issue compared to mechanical and structural failures of rotorcraft. However, there are important aspects of HEL operations that can be addressed to improve their safety. Issues of safety, comfort, communication, and regulations (see Table 2) were identified from studying the database narratives and from anecdotal evidence provided by HEL operators involved in rescue operations. Safety is critical in spite of the minimal accident history. The first recommendation is to use a passive HEL device to retain the user without the user's assistance. This would minimize the risk of falling and would allow the worker free use of the hands. The next two recommendations are that the device should maintain the worker in an upright posture and should fully secure the worker. The upright posture helps the worker remain oriented with respect to the ground and allows for the work task to be more easily executed (as in the case of power line repairs). In exceptional situations where the HEL may be accidentally tossed or even swung around, it is critical that the device fully secures the individual regardless of body orientation.

There are several other critical safety recommendations. Typically, HEL devices are attached to tethers with carabiners.

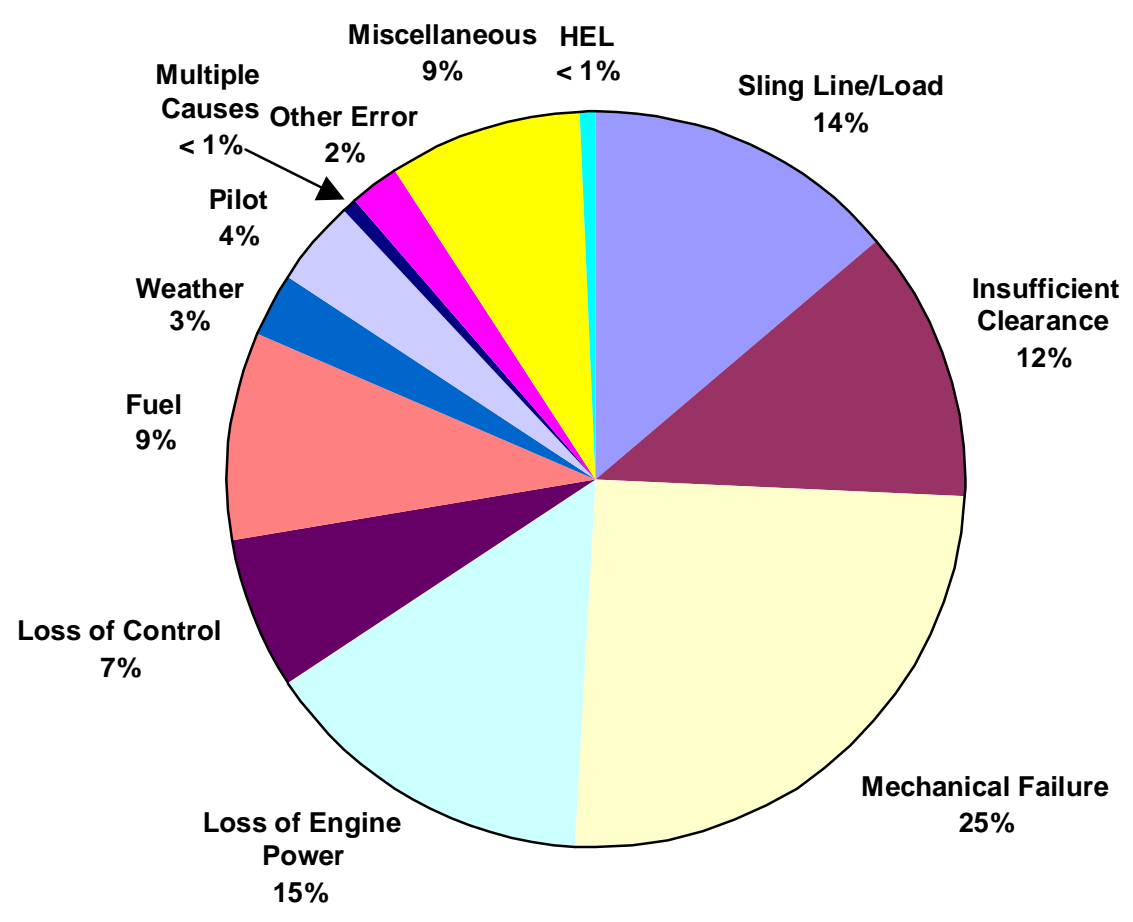

Figure 2. Categorization of Helicopter Accidents/Incidents by Primary Cause (N=616). 
Table 1. Summary of Accidents/Incidents Occurring During HEL Operations.

\begin{tabular}{|c|c|c|c|c|}
\hline Date & Source & Direct Cause & Result & Description \\
\hline $4 / 8 / 75$ & FAA & $\begin{array}{l}\text { Cable Broke } \\
\text { (Mechanical) }\end{array}$ & Injury & $\begin{array}{l}\text { Photo of hoisting operation. Cable } \\
\text { separated. Photographer fell. }\end{array}$ \\
\hline $2 / 3 / 83$ & FAA & $\begin{array}{l}\text { Loss of Control } \\
\text { (Mechanical) }\end{array}$ & 2 Injuries & $\begin{array}{l}\text { Lost control of helicopter while } 2 \text { crew on } \\
\text { sling line/load. }\end{array}$ \\
\hline $1 / 12 / 84$ & FAA & HEL & Fatality & $\begin{array}{l}\text { Trapeze performer lost grip on rope sling } \\
\text { and fell. }\end{array}$ \\
\hline $5 / 10 / 84$ & FAA & $\begin{array}{l}\text { Other Human } \\
\text { Error } \\
\text { (Communication) }\end{array}$ & No injury & $\begin{array}{l}\text { Two ground attendants fell when long line } \\
\text { was released. Pilot was unaware of their } \\
\text { presence. }\end{array}$ \\
\hline $11 / 28 / 84$ & FAA & $\begin{array}{l}\text { Pilot Error } \\
\text { (Communication) }\end{array}$ & $\begin{array}{l}\text { Fatality \& } \\
\text { Injury }\end{array}$ & $\begin{array}{l}\text { Ground crew member fell from strut. Pilot } \\
\text { misunderstood instructions. }\end{array}$ \\
\hline $5 / 23 / 90$ & $\begin{array}{l}\text { FAA } \\
\text { NTSB }\end{array}$ & $\begin{array}{l}\text { Fuel } \\
\text { Contamination } \\
\text { (Mechanical) }\end{array}$ & 2 Injuries & $\begin{array}{l}\text { Long line operations, load of equipment, } \\
\text { passengers on load. Loss of engine power } \\
\text { due to fuel contamination. }\end{array}$ \\
\hline $7 / 6 / 90$ & NTSB & $\begin{array}{l}\text { HEL } \\
\text { (Human Error) }\end{array}$ & Fatality & $\begin{array}{l}\text { Barehand live line operations. Worker } \\
\text { raised his arm, compromised the air gap. } \\
\text { Flashover and electrocution. } \\
\text { Procedures/directives not followed. }\end{array}$ \\
\hline $3 / 7 / 91$ & $\begin{array}{l}\text { FAA } \\
\text { NTSB }\end{array}$ & HEL & Fatality & $\begin{array}{l}\text { Crew attaching marker buoys to floating } \\
\text { helicopter. As raised, released hold of strap } \\
\text { and fell. }\end{array}$ \\
\hline $12 / 2 / 92$ & $\begin{array}{l}\text { FAA } \\
\text { NTSB }\end{array}$ & $\begin{array}{l}\text { Insufficient } \\
\text { Clearance - Rotor } \\
\text { (Human Error) }\end{array}$ & 2 Fatalities & $\begin{array}{l}\text { Placing marker balls on high-tension wires. } \\
\text { Main rotor struck upper guide wire. Pilot } \\
\text { misjudged the distance. }\end{array}$ \\
\hline
\end{tabular}

All carabiners should lock to avoid inadvertent release during the HEL operation. However, the locking mechanism should be simple to allow for rapid release once the HEL operation is complete. Another recommendation is that all HEL crew should wear orange safety vests either as part of the harness or as a separate garment. This would greatly enhance worker visibility for anyone monitoring the operation and may have prevented several accidents related to poor visibility. Finally, warnings and instruction labels should be affixed to the HEL device. Although the use of warnings in no way insures compliance, they should be provided for users who are seeking additional information about the device and to stimulate awareness of the hazardous nature of the operation.

Worker comfort also impacts safety because HEL devices that are comfortable and unobtrusive will more likely be used correctly and properly. The ease of donning the device, the ease of walking in the device, and the minimization of local stresses on the body are important considerations. For longterm applications (i.e., long-distance transport or longduration work), the minimization of localized stresses is important. For example, the more comfortable harness designs utilize larger width webbing covered with additional padding, and some even incorporate a cloth seat for body support. Not only will the user be more receptive to using the harness if it is comfortable, but the minimization of localized stresses on the body will reduce any short-term (i.e., numbness, pain) or long-term (i.e., permanent loss of circulation) effects of use.
Poor communication among the HEL crew factored into several accidents. Consequently, during all HEL operations, an additional crewmember should be designated as a "spotter" with no other duties than to visually monitor the HEL. For localized HEL operations, this spotter could be located on the ground, but should have continual, uninterrupted communication with the pilot. Over extended operations, the spotter should be on-board the helicopter with some method of visually monitoring the HEL. HEL crew training is also vital to communication. All HEL crewmembers should be initially trained and continually updated on basic and emergency HEL procedures. One accident was recounted by an HEL worker who described himself swinging violently towards trees. The HEL pilot over-anticipated the contact of the worker with the tree and released him seconds too early, before the worker had grabbed on to the tree. As a result, the worker fell and suffered serious injuries. The worker commented that this was a "rookie" pilot who perhaps did not fully understand the emergency procedures. Again, this scenario may have been prevented with improved HEL training.

The final recommendation is to specifically incorporate HEL operations into the Federal Aviation Regulations. The only mention of HEL found in the regulations was in reference to VFR flight. Upon talking with several HEL operators (rescue personnel), the need for clarifying the regulations became apparent, particularly in regard to the issues of competency standards and the definition of FAA "approved" 
Table 2. Considerations for FAR Modification.

\begin{tabular}{|l|}
\hline Safety \\
\hline Passive Device \\
Maintains Upright Posture \\
Individual Fully Secured \\
Locking, Easily Released Attachments to Tether \\
Safety Orange Vest \\
Warning/Instruction Labels on Equipment \\
\hline Comfort \\
\hline Ease of Donning \\
Ease of Walking \\
Minimize Localized Stress \\
\hline Communication \\
\hline "Spotter" to Visually Monitor HEL \\
Continual Training on Basic and Emergency Operations \\
\hline Regulations \\
\hline Add Information Relevant to HEL \\
Minimum Competency Standards for HEL Crew Members \\
Definition of FAA Approved Equipment \\
\hline
\end{tabular}

equipment. Currently, there is little standardization of operations among companies and rescue organizations performing HEL operations. In addition, training standards for rescue operations are vague and are open for alternate interpretation.

It is recommended that as part of this effort, competency standards and training requirements for HEL operations be introduced. The definition of FAA "approved" equipment has also troubled users. For example, the regulations refer to an FAA approved attachment point, but do not describe how to accomplish and obtain FAA approval. This definition should be clarified and expanded to incorporate other critical equipment (e.g., ropes, carabiners, and harnesses).

\section{CONCLUSIONS}

This project was undertaken with the goal of investigating the use of humans as external loads in helicopter operations. An extensive examination of accident data identified a minimal occurrence of HEL accidents, with fewer still being causally linked to the presence of HELs. Based on the recorded data, it was determined that current occupational HEL operations, although innately hazardous, do not pose excessive safety hazards to the personnel involved. However, accident narratives and operator anecdotes were used to develop guidelines for the performance of HEL operations. These guidelines addressed safety, comfort, communications, and regulations, and if adopted, would greatly enhance the safety of HEL operations. These suggested guidelines were submitted to the FAA for their consideration. To the best of the author's knowledge, the very limited occurrence of HEL accidents has postponed further regulatory action in this area.

\section{ACKNOWLEDGEMENTS}

This research was supported by the Federal Aviation Administration Civil Aeromedical Institute under Grant \#DTFA-01-95-T-80473. The authors would like to acknowledge the assistance provided by Jeffrey Marcus and David Palmerton of the FAA and of Michael Rausch of the University of Oklahoma.

\section{REFERENCES}

Accident Incident Data System (AIDS), DOT/FAA Mike Monroney Aeronautical Center, PO Box 25082, Oklahoma City, OK 73125, 1973 - 1997.

National Aeronautics and Space Administration Aviation Safety Reporting System (ASRS), 625 Ellis St. Suite 305, Mountain View, CA 94043, 1985 - 1996.

National Transportation Safety Board Accident Database, 490 L'Enfant Plaza, Washington D.C. 20954-2000, 1988 1996.

Title 14 Federal Code of Regulations (CFR) 1-1200, 1997. 